NATIONAL LABORATORY

\title{
Neutron Diffraction Residual Strain Tensor Measurements Within The Phase IA Weld Mock-up Plate P-5
}

September 12, 2011

Prepared by

Camden R. Hubbard

Diffraction and Thermophysical Properties Group

Materials Science and Technology Division

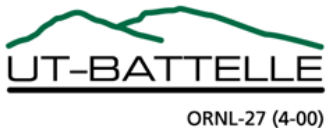




\section{DOCUMENT AVAILABILITY}

Reports produced after January 1, 1996, are generally available free via the U.S. Department of Energy (DOE) Information Bridge.

Web site http://www.osti.gov/bridge

Reports produced before January 1, 1996, may be purchased by members of the public from the following source.

National Technical Information Service

5285 Port Royal Road

Springfield, VA 22161

Telephone 703-605-6000 (1-800-553-6847)

TDD 703-487-4639

Fax 703-605-6900

E-mail info@ntis.gov

Web site http://www.ntis.gov/support/ordernowabout.htm

Reports are available to DOE employees, DOE contractors, Energy Technology Data Exchange (ETDE) representatives, and International Nuclear Information System (INIS) representatives from the following source.

Office of Scientific and Technical Information

P.O. Box 62

Oak Ridge, TN 37831

Telephone 865-576-8401

Fax 865-576-5728

E-mail reports@osti.gov

Web site http://www.osti.gov/contact.html

This report was prepared as an account of work sponsored by an agency of the United States Government. Neither the United States Government nor any agency thereof, nor any of their employees, makes any warranty, express or implied, or assumes any legal liability or responsibility for the accuracy, completeness, or usefulness of any information, apparatus, product, or process disclosed, or represents that its use would not infringe privately owned rights. Reference herein to any specific commercial product, process, or service by trade name, trademark, manufacturer, or otherwise, does not necessarily constitute or imply its endorsement, recommendation, or favoring by the United States Government or any agency thereof. The views and opinions of authors expressed herein do not necessarily state or reflect those of the United States Government or any agency thereof. 
Materials Science and Technology Division Oak Ridge National Laboratory

\title{
NEUTRON DIFFRACTION RESIDUAL STRAIN TENSOR MEASUREMENTS WITHIN THE PHASE IA WELD MOCK-UP PLATE P-5
}

\author{
Camden R. Hubbard
}

Date Published: September 2011

Prepared by OAK RIDGE NATIONAL LABORATORY

Oak Ridge, Tennessee 37831-6283

managed by

UT-BATTELLE, LLC

for the

U.S. DEPARTMENT OF ENERGY

under contract DE-AC05-00OR22725 



\section{CONTENTS}

Page

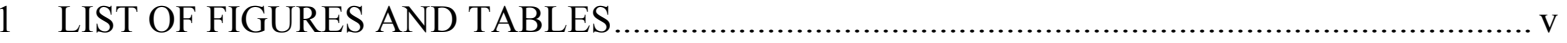

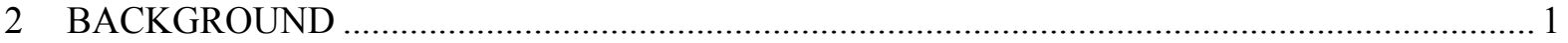

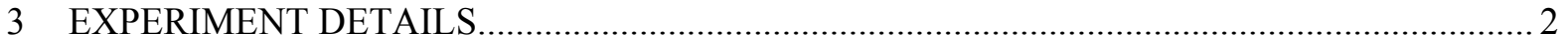

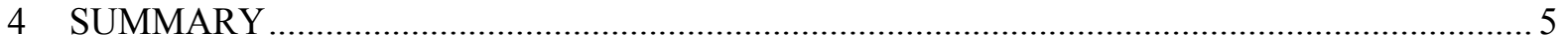

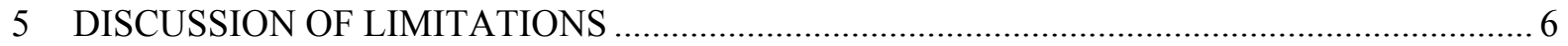

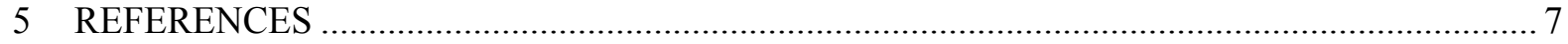

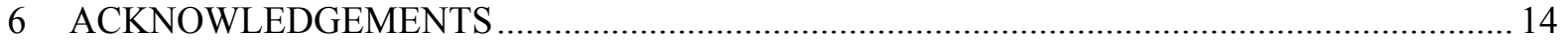





\section{LIST OF FIGURES}

Figure

Page

1. Mounting of Plate P-5 on NRSF2 for Strain Tensor Measurements............................................ 12

2. Strains for the three planes of measurement as function of depth from the top of plate.................. 13

\section{LIST OF TABLES}

1. Fabrication and Welding Details for Welding Residual Stress Validation Study .............................. 8

2. Measurements Locations in Plate Coordinate System along with the Measured Orthogonal

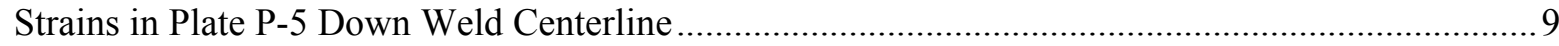

3. Measurement Conditions for Plate P-5 Tensor Data Collection .................................................... 10

4. EPRI Plate P-5 Neutron Diffraction Tensor Data Down Center of DMW .......................................11 



\title{
Neutron Diffraction Residual Strain Tensor Measurements Within The Phase IA Weld Mock-up Plate P-5
}

\author{
Prepared by: $\quad$ Camden R. Hubbard \\ Date: \\ 12 September 2011 \\ EPRI Contract Number: $\quad$ EPP27060/C12879 \\ EPRI Program Manager: Paul Crooker
}

\section{BACKGROUND}

Oak Ridge National Laboratory (ORNL) has worked with NRC and EPRI to apply neutron and $\mathrm{X}$-ray diffraction methods to characterize the residual stresses in a number of dissimilar metal weld mockups and samples. The design of the Phase IA specimens aimed to enable stress measurements by several methods and computational modeling of the weld residual stresses. The partial groove in the 304L stainless steel plate was filled with weld beads of Alloy 82. A summary of the weld conditions for each plate is provided in Table 1. The plates were constrained along the long edges during and after welding by bolts with spring-loaded washers attached to the 1" thick Al backing plate. The purpose was to avoid stress relief due to bending of the welded stainless steel plate. The neutron diffraction method was one of the methods selected by EPRI for non-destructive through thickness strain and stress measurement. Four different plates (P-3 to P-6) were studied by neutron diffraction strain mapping, representing four different welding conditions. Through thickness neutron diffraction strain mappings at NRSF2 for the four plates and associated strain-free d-zero specimens involved measurement along seven lines across the weld and at six to seven depths. ${ }^{1,2}$ The mountings of each plate for neutron diffraction measurements were such that the diffraction vector was parallel to each of the three primary orthogonal directions of the plate: two in-plane directions, longitudinal and transverse, and the direction normal to the plate (shown in left figure within Table 1). From the three orthogonal strains for each location, the residual stresses along the three plate directions were calculated. ${ }^{2}$ The principal axes of the strain and stress tensors, however, need not necessarily align with the plate coordinate system. To explore this, plate P-5 was selected for examination of the possibility that the principal axes of strain are not along the sample coordinate system axes. If adequate data could be collected the goal would be to determine the strain tensor's orientation and magnitude of strain along each principle axis direction. 


\section{EXPERIMENTAL DETAILS}

Stress measurement by neutron diffraction is often used because it is generally non-destructive, and penetrating such that it is possible to measure the through thickness stresses without cutting or sectioning. This enabled the same locations to subsequently be measured by other stress measurement techniques such as deep hole drilling (DHD) and the contour method. Neutron scattering experiments were carried out on the second generation Neutron Residual Stress Facility (NRSF2) at the HB-2B beam line of the High Flux Isotope Reactor (HFIR) at Oak Ridge National Laboratory (ORNL) ${ }^{3,4}$ Calibration of the diffractometer and the position-sensitive detectors was accomplished using a series of powder standards. ${ }^{5,6}$ The NRSF2 data collection system and sample positioner is controlled by LabView-based software NRSF2-MAP. ${ }^{7}$ The NRSF2 instrument is realigned and calibrated using a set of reference powders at the beginning of each HFIR beam cycle. ${ }^{5}$ From the calibration measurements the neutron wavelength for each monochromator setting is determined.

A frame made of $80 / 20^{*}$ high strength extruded rectangular aluminum rods was attached to the four sides of the constrained plate making a rigid frame to hold the plate and to attach it to the NRSF2 sample positioner's Z-stage of NRSF2. A laser based metrology and alignment system was used to reproducibly bring the measurement locations within the plate (four depths at mid weld location near mid length of the weld) to the intersection of the incident and diffracted beams as defined by slits defining the gauge volume of measurement. Spherical measurement reflector (SMR) nests were attached to the plate and its mounting frame. The Faro ScanArm with laser head was used to define a sample coordinate system, the location of the SMR in each nest (fiducial points), and to obtain a 3-D surface model of the sample. The surface model was derived from data collected using the laser ScanArm and Faro plug-in within GeoMagic Studio. ${ }^{8}$ The surface model derived using GeoMagic Studio from the hundreds of thousands of XYZ surface points was imported to an instrument simulation software package SScanSS. ${ }^{9,10}$ After mounting the sample on NRSF2 and measuring the locations of the fiducial SMR points in the NRSF2 sample positioner coordinate system, SScanSS then generated the sample positioner settings to precisely bring each of the defined measurement locations (Table 2) to the center of the intersection of the incident and diffracted beam slit systems (the gauge volume) which lies on the sample positioner omega axis. A few locations on the external surface of the sample were verified by neutron scanning from outside to within the sample. This method is often referred to as edge scanning. ${ }^{11,12}$ Use of SScanSS ensured that the measurements at the same locations within the sample when the sample was mounted on the NRSF2 for each of the various orientations.

For neutron measurements at NRSF2 the 80/20 frame was attached to the NRSF2 sample positioner Z-stage (Figure 1). A few of the black SMR nests can be seen in these figures attached to the plate or frame. For strain mapping for the transverse (T) strains, the weld line was vertical and the in-plane direction perpendicular to the weld was parallel to the diffraction vector. For the normal $(\mathrm{N})$ strains the weld line was vertical and the plate normal was parallel to the

\footnotetext{
* 80/20 Inc., www.8020.net, Columbia City, IN
} 
diffraction vector. For the longitudinal (L) strain measurements the weld line was horizontal, the transverse direction was vertical, and diffraction vector parallel to the weld line. For the measurement of strains at angles in between the three plate axis directions the plate was remounted to achieve a tilt in a given plane. Figure la shows a typical mounting for measurements of strains in the L-T plane. Figure $1 \mathrm{~b}$ shows a mounting for measurements of strains in the N-T plane, and Figure 1c shows a mounting for the N-L plane. Note that the range of tilt was limited in order to avoid collision of the plate with the incident or diffracted beam slit holders.

The neutron beam dimensions were determined by height and width defining slits on the incident beam side and a width defining slit on the diffracted beam side. These slits are placed in the slit holder, and the offset of the slits from the gauge volume is set by radially positioning the slit holder. Table 3 lists the particular slit sizes and slit offsets from the center of the gauge volume, the monochromator selection and its neutron wavelength.

For the transverse and normal strain measurements the slits defined a gauge volume of $2 \times 20 \times 2$ $\mathrm{mm}^{3}$, taking advantage that the strains are approximately equal for any location along the weld line for these two components. For the longitudinal strain measurements the gauge volume was $2 \times 2 \times 2 \mathrm{~mm}^{3}$. For all tilts between $0^{\circ}$ and $+/-90^{\circ}$ the near cubic gauge volume of $2 \times 2 \times 2 \mathrm{~mm}^{3}$ was also used. Due to the size of the gauge volume, depths of penetration and corresponding count times, the measurements were restricted to four depths through the plate at the mid weld line (line 4 in the full stress mapping of plate P-5). Measurements along the center of the weld line avoided the zones near the stainless steel-A82 weld metal interfaces of the weld. However, these mid weld locations are still subject to both chemical mixing of the Alloy 82 and 304L SS austenitic alloys during welding (affecting d-zero) and grain growth during cooling.

Measurements to obtain the P-5 strain orientation dependent data were performed in two beam cycles at the NRSF2. A stainless steel portion of a rod cut from a similar welded plate (P-2) was measured before and after the four depth measurements for every data set and then checked for consistency of d-spacing. Typically the two measurements agreed within the measurement uncertainty. In one case this d-spacing changed significantly indicating a collision of the plate with the slit systems occurred during measurements. The data points after the collision were omitted from the analysis. The average of the repeat measurements was used to scale all the data to a common d-spacing scale. Following all the strain measurements at NRSF2 for Plate P-5 a 5 mm thick slab was water jet cut from across the weld region about 3" from mid weld toward one end of the plate. The slab was then electron discharge machine (EDM) cut to make a comb with teeth located at eleven locations across the weld. The d-spacings from all the teeth at each depth of measurement were recorded. The same P-2 reference bar was also measured with the d-zero comb for Plate P-5 so that the stress-free d-spacings for the comb could also be brought to the same scale. The scaled d-zero values are reported in reference 2 . The d-zero values exhibit some dependence on orientation and thus, to derive a d-zero for the tilted mountings for each depth we used a weighted average of the d-zero for that tilt. The count times for measurement with the 8 $\mathrm{mm}^{3}$ gauge volume varied from a few minutes up to 80 minutes for the N-T and N-L measurements through thickness as the incident and diffracted beam path lengths increase with depth. Measurements were made at 10 different orientations of the plate: 1 each along the plate $\mathrm{L}, \mathrm{T}$ and $\mathrm{N}$ directions, at tilts of 32,45 and $60^{\circ}$ in the L-T plane, 30 and $-32^{\circ}$ in the N-L plane, 
and 28 and $-24^{\circ}$ in the N-T plane. Potential collisions of the plate with the slit holders limited the extent of tilting. Limits on allocation of beam time prevented measurement of negative tils in the L-T plane. Measurements were made near the mid length of the weld along a line down the center of the Alloy 82 weld pool at depths of 2.0 (N-L tilts only), 4.4, 6.8, 9.2 and $11.6 \mathrm{~mm}$.

Diffraction peak profiles were fit with a pseudo Voigt profile model plus a linear background to determine the peak position $(2 \theta)$ as well as peak intensity, profile breadth, and the associated estimated standard deviations (e.s.d.'s) using the LabView-based software NRSF2-VIEW. ${ }^{6}$ With Bragg's Law and wavelength, the d-spacing (Eq. 1) and its measurement e.s.d. were calculated

$$
d_{h k l}=\frac{\lambda}{2 \cdot \sin \theta_{h k l}}
$$

where $\lambda$ is the wavelength of the neutrons and $\theta_{h k l}$ is half the scattering angle for a diffraction peak corresponding to the crystallographic Miller indices $h, k, l$. The ferritic carbon steel (211) peak and the austenitic A182 weld metal and stainless steel (311) were used in this study. The diffraction peaks for the Si331 monochromator, $\lambda \sim 1.729 \AA$, are located around $95.0^{\circ}$ and $106.25^{\circ} 2 \theta$, respectively. For the Si511 monochromator, $\lambda \sim 1.449 \AA$, they are located around $76.6^{\circ}$ and $85.5^{\circ}$, respectively.

The stainless steel reference bar was measured in every experimental run at the beginning and end of the depth measurements for each tilt. The d-spacings for the replicate measurements were averaged and results checked to confirm that all were consistent (i.e., within the e.s.d.'s of the measurement). Using the average $d$-spacing of the stainless steel reference bar for each run, the d-spacings for the plate were then brought to a common scale. The same stainless steel reference bar was also measured along with the stress free comb and similarly used to adjust them to the same common scale. From the sets of scaled d-spacings for the plate P-5 in various tilts and the comb, the strains were then determined (Eq. 2) from the change in interplanar spacing for each location

$$
\varepsilon_{h k l}=\frac{\left(d_{h k l}-d_{h k l}^{o}\right)}{d_{h k l}^{o}}
$$

where $\varepsilon_{\mathrm{hkl}}$ is the elastic residual strain, $d_{h k l}^{o}$ is the interplanar spacing of the stress-free reference.

A propagation of errors approach was used to calculate an estimated standard deviation of the strains using the estimated standard deviations for the d-spacings and the scale factors. Table 4 lists the measurement planes, tilt angles within the plane and depth from the top of the plate along with the scaled d-spacings, scaled d-zero, and calculated strains with their e.s.d.'s. Uncertainty estimates only represent the uncertainty arrived from profile fitting (counting statistics based). Taking into account the larger uncertainty due to position would likely increase these several fold due to the known large changes in d-zero with chemistry due to mixing of the two austenitic phases. 


\section{SUMMARY}

Measurements to test if the $\mathrm{L}, \mathrm{T} \& \mathrm{~N}$ plate coordinates are the principle axes for the residual strains were collected at four depths down the centerline of the dissimilar metal weld in EPRI mock-up plate P-5. Strains were obtained for four orientations in the Normal-Transverse plane, four orientations in the Normal-Longitudinal plane, and five orientations in the LongitudinalTransverse plane. For one of the tilts in the N-L plane there was a collision of the sample with the slit system and only the first depth $(2.0 \mathrm{~mm})$ had reliable data. Time limitations prevented collecting data at negative tilts in the T-L plane that would be valuable to the interpretation of strain tensor orientation and magnitude. In the N-L and N-T cases, the potential of collisions prevented measurements with larger tilts.

In the Normal-Transverse plane (N-T, Figure 2c) the largest magnitude strains are parallel to the transverse direction. The strains values for the $-24^{\circ}$ and $+28^{\circ}$ tilts from the plate normal are nearly equal for each depth, that is symmetric about the strain at $0^{\circ}$ tilt (Normal direction). These two results suggest that within the N-T plane the principal axes of strain are parallel to the transverse and the normal directions of the plate.

In the Normal-Longitudinal plane (N-L, Figure $2 b)$ the loss of data at $-32^{\circ}$ tilt for most depths limits the interpretation. However, the strain data for $2.01 \mathrm{~mm}$ depth at for four tilts $\left(-32^{\circ}, 0^{\circ}\right.$, $+30^{\circ}$ and $90^{\circ}$ ) lie close to a line symmetric about $0^{\circ}$. For depths $4.4,6.8$ and $9.2 \mathrm{~mm}$ the N-L strains all have positive slopes from $0^{\circ}$ to $90^{\circ}$ the data suggests that, in the N-L plane, the principal axes of strain lie close to the Normal and Longitudinal directions. For depth $11.6 \mathrm{~mm}$ in the N-L plane the minimum value is at $+30^{\circ}$ tilt suggesting that within the $304 \mathrm{~L}$ land the principle axis of residual strain may be tilted away from the $\mathrm{N}$ and $\mathrm{L}$ directions.

In the Transverse-Longitudinal plane (T-L, Figure 2a) the lack of data at negative tilts limits full interpretation. However, it is clear that for the depth $11.6 \mathrm{~mm}$ (within the 304L SS land below the weld metal) that the strains are compressive in the transverse direction and trend to slightly tensile in the longitudinal direction. Within the weld metal (depths 4.4, 6.2 and $9.2 \mathrm{~mm}$ ) the strain values are generally tensile, but vary from a smooth line quite significantly at tilts of $45^{\circ}$ and $58^{\circ}$. The smooth trends for the N-L and N-T planes and for the $11.6 \mathrm{~mm}$ depth in the T-L plane suggest these large swings in strain for $45^{\circ}$ and $58^{\circ}$ are related to weld bead localized residual strains and that the principal axes are rotated significantly from the primary axes of the plate.

Because of an insufficient number of tilts and particularly few data points for negative tilts the interpretation of the data for principal axes orientation and direction has been restricted to a the qualitative analysis above. Further, the indication of weld bead to weld bead localized residual strains in the T-L plane indicate that the data do not fit to a standard strain tensor model. Numerical analyses could be tried but trials indicated it will be of limited accuracy and thus are not reported. 


\section{DISCUSSION OF LIMITATIONS}

The measurement of strains in ten or more different directions relative to the sample coordinate system for the large, constrained mock-up EPRI Phase IA plate P-5 was shown to be feasible. The use of the laser tracker along with SScanSS software substantially minimized time of alignment for the ten mountings and helped keep the time for the total experiment reasonable. Strain data obtain in the stainless steel plate under the weld (depth $11.6 \mathrm{~mm}$ ) varied smoothly for all three planes of measurement. The strains for depths 4.4, 6.8 and $9.2 \mathrm{~mm}$ were all within the Alloy 82 weld metal and varied smoothly with tilt angle in the N-L and N-T planes. However, the measurements in the weld metal for the L-T plane show substantial variation as a function of tilt angle that we believe are indicative of a possible rotation of the principal axes of strain in that plane due to weld bead to weld bead interactions. Further measurements would be needed to confirm this possible explanation.

Measurements of the strain tensor at locations in the plane of the plate perpendicular to the weld center line nearer the stainless steel to weld metal interface were not made. These locations have a greater probability of rotation of the strain tensor but are also very sensitive to the changes in dzero with location and in some cases have been shown to involve a "buried interface" as would be shown by diffraction peaks from both the 304L SS and the Alloy 82 weld metal instead of a homogeneous, single-phase diffraction pattern. Thus the sample phases and microstructure for these mock-up specimens make the study of tensor orientation near the weld edges problematic and present additional challenges.

During the course of the study the following limitations to using neutron diffraction strain mapping for determination of the strain tensor across the 304L SS -Alloy 82 welds were recognized. First, the gauge volume should be cubic and small enough not to average over large changes in the d-zero values or strain gradients in the specimen. However, for accurate measurement of the diffraction peak position there needs to be sufficient grains contributing to the diffraction profile while the count time needs to be kept within reason. The $2 \times 2 \times 2 \mathrm{~mm}^{3}$ gauge volume seemed to be a reasonable compromise. Second, the count times are long at the locations within the specimen with long neutron beam paths, and hence the number of possible measurement locations was limited given the availability of neutron time. Additional locations, and particularly some in the stainless steel adjacent to the weld metal interface ideally should have been measured as the strain tensor in the weld metal at those locations near the interface should show the strongest reorientation of the principle axes. Third, the large plate specimen shape and the backing plate and restraining bolts further limited the ability to measure strains in additional directions. Fourth, more than 2 or 3 tilts in each plane are needed for determination of the 2-D strain tensor in a given plane. In particular, tilts in both directions about each of the standard axes of the plate should be obtained. 


\section{REFERENCES}

1. Hubbard, C.R., T.R. Watkins, R. Peascoe, J. Pineault, S. Van De Car, Z. Feng, F. Ren, W. Zhang, J. Schmidlin, B. Cady and M. Klug, Dissimilar Metal Weld Residual Stress Mapping by Neutron and X-ray Diffraction and Incremental Hole Drilling Methods, Residual Stress Summit, Tahoe City, CA (Sept. 2010).

2. Hubbard, C.R., Neutron Diffraction Residual Stress Mapping of Four Mock-up Plates for Validation of FEA Models of Dissimilar Metal Welds, ORNL/TM 2011/305, (2011)

3. See http://neutrons.ornl.gov/instruments/HFIR/HB2B/ and http://neutrons.ornl.gov/instruments/HFIR/factsheets/Instrument_hb2b.pdf

4. Bailey, W.B. Design of a Detector Array for Neutron Residual Stress Measurement at Oak Ridge National Laboratory's High Flux Isotope Reactor. Columbia MS Thesis University of South Carolina, (2005).

1. Tang, F. and Hubbard, C.R. Calibration of NRSF2 Instrument at HFIR, ORNL/TM2006/541 (2006).

2. An, K. and Hubbard, C.R. User Manual of the NRSF2-VIEW and NRSF2CALIBRATE, ORNL/TM-2005/530 (2006).

3. An, K. Wright, M.C. and Hubbard, C.R. User Manual of NRSF2-MAP, ORNL/TM 2005/531 (2006).

4. Bunn, J., Schmidlin, J. and Hubbard, C.R. Residual Stress Sample Alignment Laboratory Guideline, ORNL/TM-2008/159 (2008).

5. James, J.A., et al $A$ virtual laboratory for neutron and synchrotron strain scanning, Physica B, Vol 350, E743-6 (2004).

6. James, J.A. and Edwards, L., Application of robot kinematics methods to the simulation and control of neutron beam line positioning systems, Nuclear Instruments and Methods in Physics Research A., 571 (2007).

7. Wang, D.-Q., X.-L. Wang, and Hubbard, C.R. Precise Determination of Sample Position with a Radial Collimator and/or Slit(s) for Stress measurements via Neutron Diffraction, The Sixth International Conference on Residual Stresses, Volume 2, 12551263 (2000)

8. Wang, X.-L., Spooner, S. and Hubbard, C.R., Theory of the Peak Shift Anomaly due to Partial Burial of the Sampling volume in Neutron Diffraction Residual Stress Measurements, J. Appl. Cryst., 30, 52-59 (1998). 

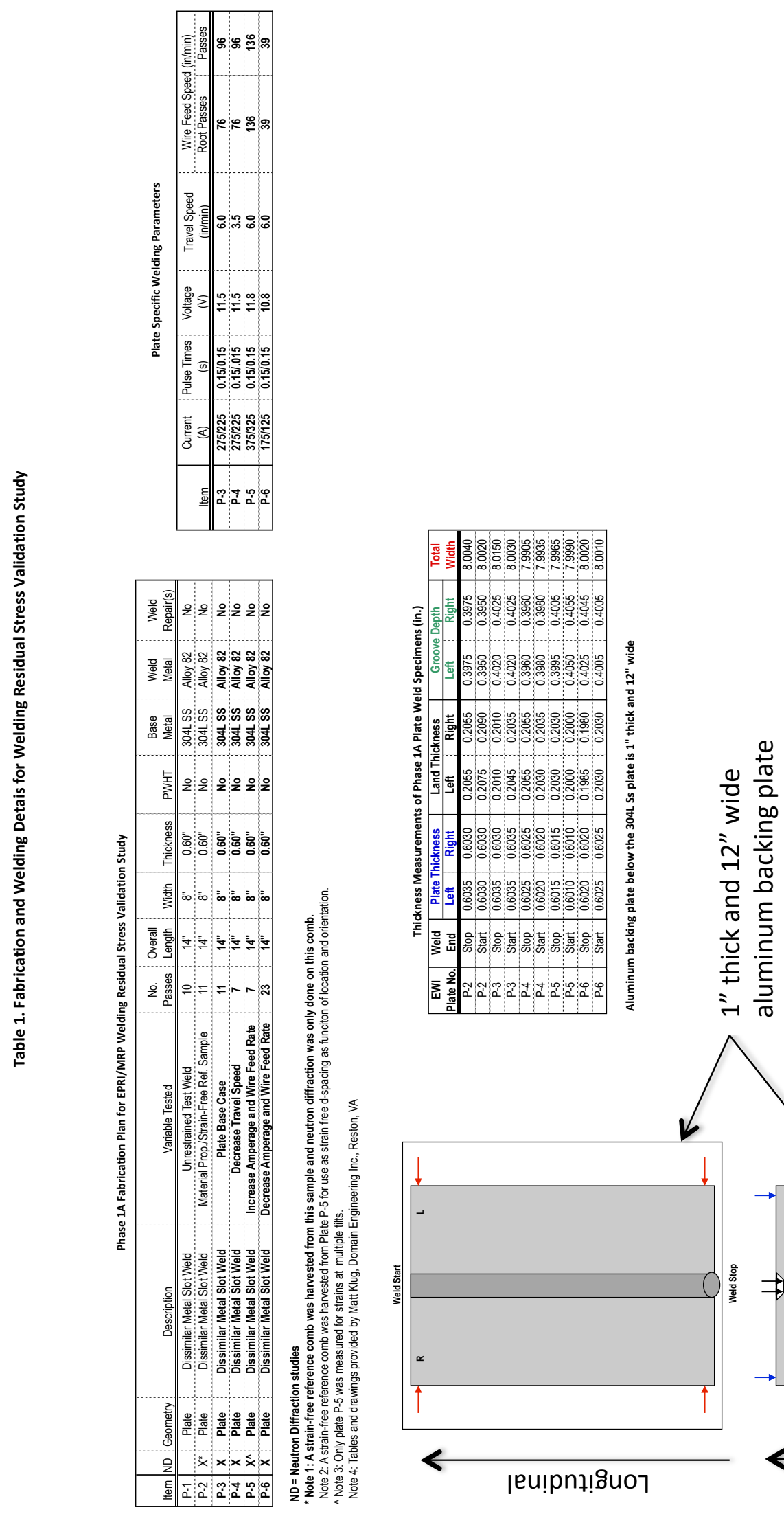

$\infty$

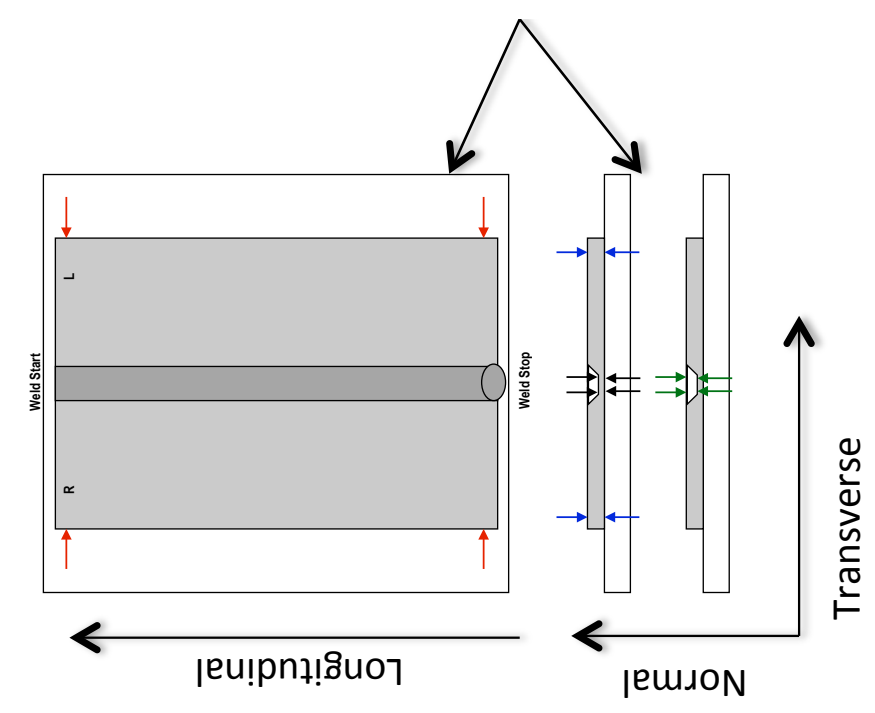




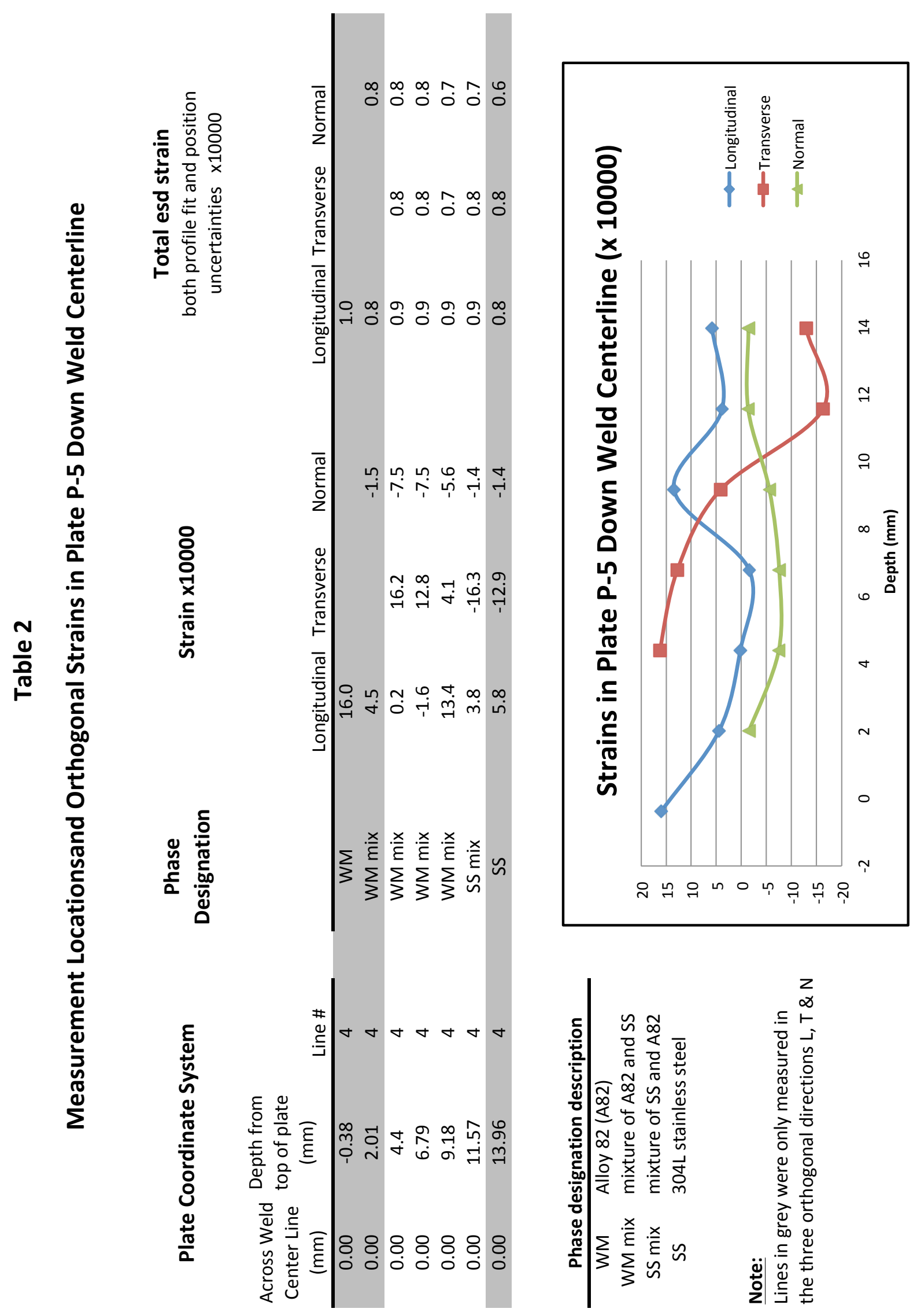




\begin{tabular}{|c|c|c|c|c|c|c|}
\hline 䓂高 & R & 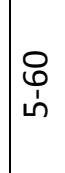 & 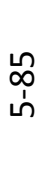 & $\sigma$ & i & $\mid \begin{array}{l}0 \\
i \\
1 \\
i \\
0\end{array}$ \\
\hline 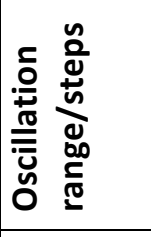 & 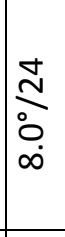 & 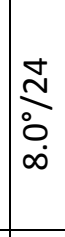 & 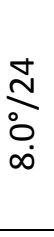 & 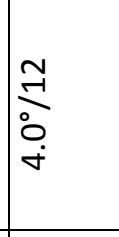 & $\mid \begin{array}{l}\tilde{I} \\
\vdots \\
\dot{\sigma} \\
\dot{\sigma}\end{array}$ & 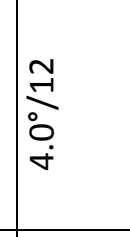 \\
\hline 䓤 & $\underset{\dot{\infty}}{\dot{\infty}}$ & 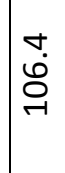 & $\begin{array}{l}\text { ¿̊ } \\
\text { d }\end{array}$ & ¿ & 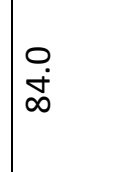 & 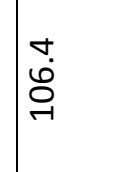 \\
\hline 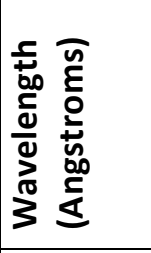 & $\mid$ & 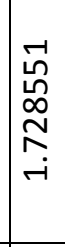 & 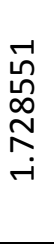 & 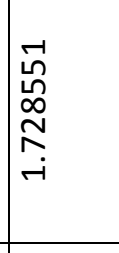 & | & 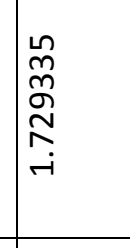 \\
\hline 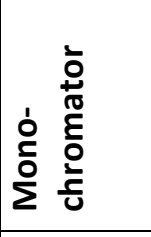 & ت्ञ & $\begin{array}{l}\vec{m} \\
m \\
i n\end{array}$ & $\begin{array}{l}\vec{m} \\
i \vec{n}\end{array}$ & 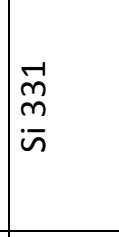 & $\frac{\overrightarrow{7}}{i n}$ & $\begin{array}{l}\vec{p} \\
\bar{m} \\
\bar{m}\end{array}$ \\
\hline 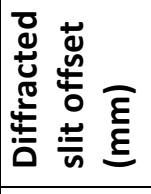 & ก & શి & 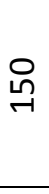 & : & $\infty$ & $\bumpeq$ \\
\hline 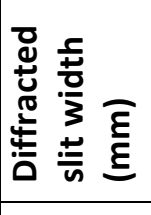 & $\sim$ & $\sim$ & $\sim$ & $\sim$ & N & N \\
\hline 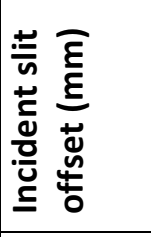 & $\stackrel{n}{n}$ & & $\infty$ & $\stackrel{n}{\wedge}$ & 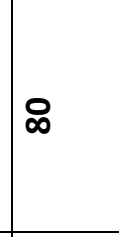 & $\stackrel{n}{\kappa}$ \\
\hline 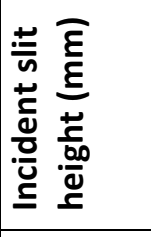 & $\sim$ & $\sim$ & $\sim$ & $\stackrel{i}{i}$ & N & i \\
\hline 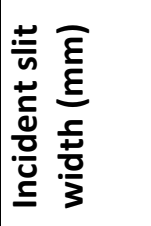 & $\sim$ & $\sim$ & $\sim$ & N & N & N \\
\hline 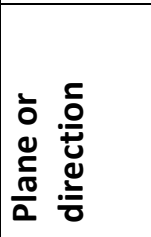 & 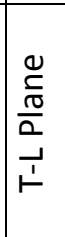 & $\begin{array}{l}\frac{\tilde{c}}{0} \\
\frac{\pi}{2} \\
\frac{1}{z}\end{array}$ & $\begin{array}{l}\frac{0}{2} \\
\frac{\pi}{0} \\
\frac{1}{2} \\
\frac{1}{2}\end{array}$ & 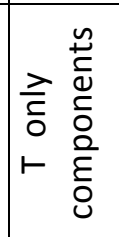 & 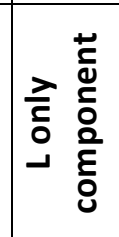 & 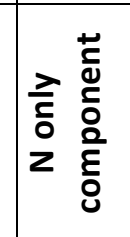 \\
\hline
\end{tabular}


Table 4

EPRI PLATE P-5 Neutron Diffraction Tensor Data Down Center of Alloy 82 Weld

\begin{tabular}{|c|c|c|c|}
\hline Equation & & & \\
\hline Angle & data set & Tilt angle & $\cos (p$ \\
\hline 90.00 & 9.0 & 0.00 & \\
\hline 60.00 & 1.0 & 30.00 & \\
\hline 45.00 & 3.0 & 45.00 & \\
\hline 32.00 & 4.0 & 58.00 & \\
\hline 0.00 & 8.0 & 90.00 & \\
\hline 90.00 & 9.0 & 0.00 & \\
\hline 60.00 & 1.0 & 30.00 & \\
\hline 45.00 & 3.0 & 45.00 & \\
\hline 32.00 & 4.0 & 58.00 & \\
\hline 0.00 & 8.0 & 90.00 & \\
\hline 90.00 & 9.0 & 0.00 & \\
\hline 60.00 & 1.0 & 30.00 & \\
\hline 45.00 & 3.0 & 45.00 & \\
\hline 32.00 & 4.0 & 58.00 & \\
\hline 0.00 & 8.0 & 90.00 & \\
\hline 90.00 & 9.0 & 0.00 & \\
\hline 60.00 & 1.0 & 30.00 & \\
\hline 45.00 & 3.0 & 45.00 & \\
\hline 32.00 & 4.0 & 58.00 & \\
\hline 0.00 & 8.0 & 90.00 & \\
\hline
\end{tabular}

T-L

Scane Ang

(from Scaled D

comb) (from P-5)

$\begin{array}{llllll}1.079452 & 1.081203 & 0.000011 & 0.000018\end{array}$

$\begin{array}{lllll}1.079933 & 1.080147 & 0.000011 & 0.000090\end{array}$

$\begin{array}{lllll}1.080109 & 1.079674 & 0.000011 & 0.000023\end{array}$

$\begin{array}{lllll}1.080261 & 1.081289 & 0.000000 & 0.000026\end{array}$

$\begin{array}{lllll}1.080767 & 1.080790 & 0.000013 & 0.000024\end{array}$

$\begin{array}{lllll}1.079566 & 1.080943 & 0.000012 & 0.000014\end{array}$

$\begin{array}{lllll}1.080193 & 1.081301 & 0.000012 & 0.000042\end{array}$

$\begin{array}{lllll}1.080423 & 1.080722 & 0.000012 & 0.000021\end{array}$

$\begin{array}{llll}1.080620 & 1.083538 & 0.000016 & 0.000022\end{array}$

$\begin{array}{lllll}1.081279 & 1.081108 & 0.000016 & 0.000034\end{array}$

$\begin{array}{lllll}1.080789 & 1.081234 & 0.000011 & 0.000010\end{array}$

$\begin{array}{lllll}1.080193 & 1.081301 & 0.000012 & 0.000042\end{array}$

$\begin{array}{lllll}1.081174 & 1.082213 & 0.000011 & 0.000020\end{array}$

$\begin{array}{lllll}1.081264 & 1.083838 & 0.000013 & 0.000021\end{array}$

$\begin{array}{lllll}1.081560 & 1.083012 & 0.000000 & 0.000031\end{array}$

$\begin{array}{llll}1.083196 & 1.081434 & 0.000013 & 0.000011\end{array}$

$\begin{array}{lllll}1.083467 & 1.082134 & 0.000013 & 0.000014\end{array}$

$\begin{array}{lllll}1.083566 & 1.083024 & 0.000013 & 0.000017\end{array}$

$\begin{array}{lllll}1.083651 & 1.083643 & 0.000010 & 0.000018\end{array}$

$\begin{array}{llll}1.083935 & 1.084352 & 0.000010 & 0.000035\end{array}$
Esd Strain Depth

$\begin{array}{ccc}\text { Strain * 10000 } & * 10000 & (\mathbf{m m}) \\ 16.23 & 0.20 & 4.40 \\ 1.98 & 0.84 & 4.40 \\ -4.03 & 0.24 & 4.40 \\ 9.52 & 0.24 & 4.40 \\ 0.22 & 0.25 & 4.40 \\ 12.76 & 0.17 & 6.80 \\ 10.25 & 0.40 & 6.80 \\ 2.77 & 0.22 & 6.80 \\ 27.00 & 0.25 & 6.80 \\ -1.59 & 0.35 & 6.80 \\ 4.12 & 0.14 & 9.20 \\ 10.25 & 0.40 & 9.20 \\ 9.60 & 0.21 & 9.20 \\ 23.81 & 0.23 & 9.20 \\ 13.42 & 0.29 & 9.20 \\ -16.27 & 0.16 & 11.60 \\ -12.30 & 0.18 & 11.60 \\ -5.00 & 0.20 & 11.60 \\ -0.08 & 0.19 & 11.60 \\ 3.84 & 0.34 & 11.60\end{array}$

\section{Normal-Longitudinal Strains vs In-Plane Angle}

\subsection{0}

90.00

60.00

0.00

122.00

90.00

60.00

0.00

122.00

90.00

60.00

0.00

122.00

90.00

60.00

0.00

122.00

90.00

60.00

0.00
$60-32.00$

10.0

$-32.00$

0.00

$-0.53$

0.00

0.00
0.50

2.0

30.00

90.00

$6.0 \quad-32.00$

10.0

0.00

1.00

$-0.53$

0.00

30.00

$\begin{array}{ll}8.0 & 90.00 \\ 6.0 & -32.00\end{array}$

10.0

0.00

0.50

1.00

$-0.53$

0.00

0.50

1.00

$8.0 \quad 90.00$

$\begin{array}{ll}8.0 & -32.00\end{array}$

$\begin{array}{ll}10.0 & 0.00\end{array}$

2.0

30.00

$8.0 \quad 90.00$

$6.0 \quad-32.00$

$\begin{array}{ll}10.0 & 0.00\end{array}$

$2.0 \quad 30.00$

$8.0 \quad 90.00$

0.00

0.50

1.00

$-0.53$

0.00

0.50
1.00 $\begin{array}{llll}1.079592 & 1.079798 & 0.000020 & 0.000002\end{array}$

$\begin{array}{llll}1.079323 & 1.079160 & 0.000020 & 0.000014\end{array}$

$\begin{array}{lllll}1.079579 & 1.079408 & 0.000020 & 0.000004\end{array}$

$\begin{array}{lllll}1.080022 & 1.080503 & 0.000000 & 0.000024\end{array}$ bump

$\begin{array}{llll}1.079872 & 1.079066 & 0.000020 & 0.000011\end{array}$

$\begin{array}{llll}1.080199 & 1.079655 & 0.000020 & 0.000005\end{array}$

$\begin{array}{lllll}1.080767 & 1.080790 & 0.000013 & 0.000024\end{array}$ bump

$\begin{array}{llll}1.080421 & 1.079606 & 0.000020 & 0.000011\end{array}$

$\begin{array}{llll}1.080735 & 1.079986 & 0.000020 & 0.000008\end{array}$

$\begin{array}{llll}1.081279 & 1.081108 & 0.000016 & 0.000034\end{array}$

$\begin{array}{rr}\text { bump } \\ 1.080969 & 1.080365\end{array}$

$\begin{array}{lllll}1.081186 & 1.080849 & 0.000011 & 0.000012\end{array}$

$\begin{array}{llll}1.081560 & 1.083012 & 0.000000 & 0.000031\end{array}$ bump

$\begin{array}{llll}1.082898 & 1.082751 & 0.000011 & 0.000007\end{array}$

$\begin{array}{lllll}1.083277 & 1.082104 & 0.000011 & 0.000020\end{array}$

$\begin{array}{llll}1.083935 & 1.084352 & 0.000010 & 0.000035\end{array}$

1.083935
and data lost

$\begin{array}{ccc}1.90 & 0.19 & 2.01 \\ -1.51 & 0.23 & 2.01 \\ -1.59 & 0.19 & 2.01 \\ 4.46 & 0.22 & 2.01 \\ & & 4.40 \\ -7.46 & 0.21 & 4.40 \\ -5.04 & 0.19 & 4.40 \\ 0.22 & 0.25 & 4.40 \\ & & 6.80 \\ -7.54 & 0.21 & 6.80 \\ -6.93 & 0.20 & 6.80 \\ -1.59 & 0.35 & 6.80 \\ & & 9.20 \\ -5.59 & 0.10 & 9.20 \\ -3.12 & 0.15 & 9.20 \\ 13.42 & 0.29 & 9.20 \\ & & 11.60 \\ -1.36 & 0.12 & 11.60 \\ -10.83 & 0.21 & 11.60 \\ 3.84 & 0.34 & 11.60\end{array}$

Normal-Transverse Strains vs In-Plane Angle

$\mathrm{N}-\mathrm{T}$

$\begin{array}{ccccccccccc}114.00 & 5.0 & -24.00 & -0.41 & 1.079742 & 1.079682 & 0.000020 & 0.000003 & -0.56 & 0.19 & 4.40 \\ 90.00 & 10.0 & 0.00 & 0.00 & 1.079872 & 1.079066 & 0.000020 & 0.000011 & -7.46 & 0.21 & 4.40 \\ 62.00 & 7.0 & 28.00 & 0.47 & 1.079726 & 1.079586 & 0.000020 & 0.000008 & -1.29 & 0.20 & 4.40 \\ 0.00 & 9.0 & 90.00 & 1.00 & 1.079452 & 1.081203 & 0.000011 & 0.000018 & 16.23 & 0.20 & 4.40 \\ 114.00 & 5.0 & -24.00 & -0.41 & 1.080157 & 1.080407 & 0.000020 & 0.000006 & 2.31 & 0.19 & 6.80 \\ 90.00 & 10.0 & 0.00 & 0.00 & 1.080421 & 1.079606 & 0.000020 & 0.000011 & -7.54 & 0.21 & 6.80 \\ 62.00 & 7.0 & 28.00 & 0.47 & 1.080124 & 1.079916 & 0.000020 & 0.000014 & -1.92 & 0.23 & 6.80 \\ 0.00 & 9.0 & 90.00 & 1.00 & 1.079566 & 1.080943 & 0.000012 & 0.000014 & 12.76 & 0.17 & 6.80 \\ 114.00 & 5.0 & -24.00 & -0.41 & 1.080914 & 1.081226 & 0.000011 & 0.000009 & 2.89 & 0.13 & 9.20 \\ 90.00 & 10.0 & 0.00 & 0.00 & 1.080969 & 1.080365 & 0.000011 & 0.000000 & -5.59 & 0.10 & 9.20 \\ 62.00 & 7.0 & 28.00 & 0.47 & 1.080907 & 1.080848 & 0.000011 & 0.000030 & -0.55 & 0.30 & 9.20 \\ 0.00 & 9.0 & 90.00 & 1.00 & 1.080789 & 1.081234 & 0.000011 & 0.000010 & 4.12 & 0.14 & 9.20 \\ 114.00 & 5.0 & -24.00 & -0.41 & 1.082990 & 1.082630 & 0.000011 & 0.000018 & -3.32 & 0.19 & 11.60 \\ 90.00 & 10.0 & 0.00 & 0.00 & 1.082898 & 1.082751 & 0.000011 & 0.000007 & -1.36 & 0.12 & 11.60 \\ 62.00 & 7.0 & 28.00 & 0.47 & 1.083001 & 1.082881 & 0.000011 & 0.000285 & -1.11 & 2.63 & 11.60 \\ 0.00 & 9.0 & 90.00 & 1.00 & 1.083196 & 1.081434 & 0.000013 & 0.000011 & -16.27 & 0.16 & 11.60\end{array}$



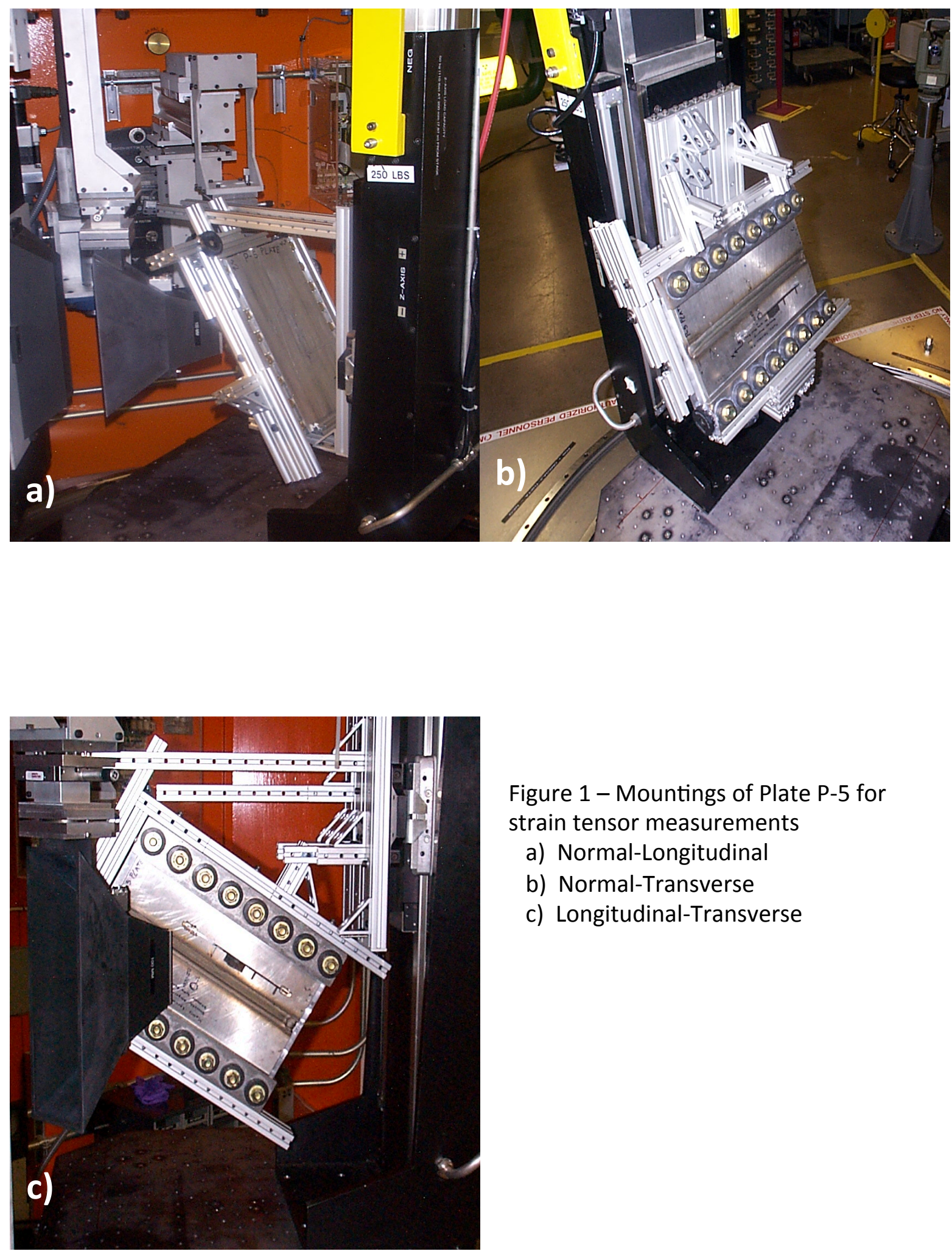

Figure 1 - Mountings of Plate P-5 for strain tensor measurements

a) Normal-Longitudinal

b) Normal-Transverse

c) Longitudinal-Transverse 

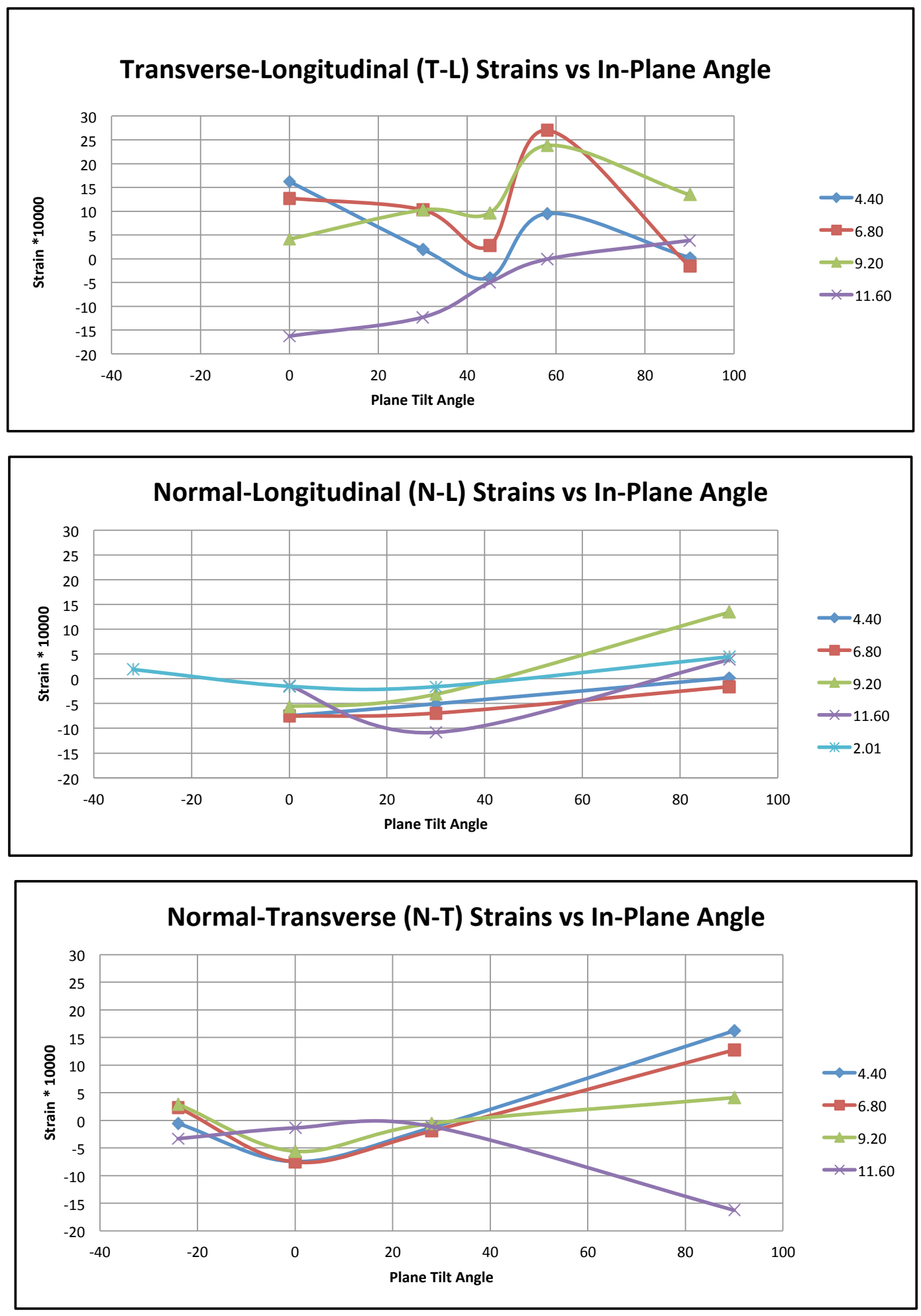

Figure 2. Strains for the three planes of measurement as a function of depth from the top of plate a) T-L plane. The $0^{\circ}$ tilt anlge corresponds to the transverse direction

b) N-L plane. The $0^{\circ}$ tilt angle corresponds to the Normal direction.

c) N-T plane. The $0^{\circ}$ tilt angle corresponds to the Normal direction. 


\section{ACKNOWLEDGEMENTS}

The Nuclear Regulatory Commission (NRC) and Electric Power Research Institute (EPRI) are working together under a MOU to advance the validation of modeling of dissimilar metal welds used in nuclear reactors. ORNL has been funded by EPRI for measurements on the Phase IA plates and Phase IB cylinders. The neutron strain mapping characterization of the Strain Tensor at Mid Weld for Plate P-5, a portion of the overall project, was funded by EPRI under contract EPP27060/C12879. The encouragement and guidance of program manager Paul Crooker (EPRI) as well as that of Howard Rathbun (NRC) and Al Csontos (NRC) is much appreciated.

The work at ORNL involved a number of team members' contributions: Josh Schmidlin led preparation of the mounting and metrology of the plates and the preparation of the stress free combs. He was also a major contributor to the measurement efforts. Mr. Brian Cady performed the major fraction of the data processing and bringing all the data to a common scale, calculation of the strains and stresses, and preparation of plots. Dr. Tom Watkins was gracious to provide many suggestions to improve the manuscript.

Most of the equipment and instrumentation utilized during this investigation was acquired and maintained by the Oak Ridge National Laboratory's High Temperature Materials Laboratory User Program, which is sponsored by the U. S. Department of Energy, Office of Energy Efficiency and Renewable Energy, Vehicle Technologies Program. This research was conducted at the High Flux Isotope Reactor, which is sponsored at Oak Ridge National Laboratory by the Division of Scientific User Facilities, U.S. Department of Energy. 